\title{
Genetic polymorphism in Taenia solium metacestodes from different Brazilian geographic areas
}

\author{
Ivanildes Solange da Costa Barcelos ${ }^{1,2}$, Maria Aparecida Souza ${ }^{3}$, Janethe Deolinda de Oliveira Pena ${ }^{3}$, \\ Gleyce Alves Machado',4, Lísia Gomes Martins de Moura1', Julia Maria Costa-Cruz¹/+ \\ 1'Laboratório de Diagnóstico de Parasitoses ${ }^{3}$ Laboratório de Biologia Molecular, Instituto de Ciências Biomédicas, \\ Universidade Federal de Uberlândia, Av. Pará 1720, 38400-902 Uberlândia, MG, Brasil Laboratório de Ciências Biomédicas - \\ Imunologia, Campus Jataí ${ }^{4}$ Departamento de Ciências Biológicas, Campus Catalão, Universidade Federal de Goiás, Goiânia, GO, Brasil
}

The aim of the present study is to investigate genetic polymorphisms in Taenia solium metacestodes from different Brazilian geographical areas and to relate them to antibody recognition in serum samples of neurocysticercosis (NC) patients. Metacestodes were obtained from the Distrito Federal (DF), Bahia, Minas Gerais (MG) and São Paulo (SP) regions of Brazil. Samples of human sera from 49 individuals with NC, 68 individuals with other helminthiasis and 40 healthy volunteers were analysed (157 individuals in total). Antigens were prepared and used in enzyme-linked immunosorbent assay and western blotting assays to detect specific immunoglobulin G antibodies. Genetic distances between metacestode populations were analysed using random amplified polymorphic DNA $(R A P D)$ analysis. Our results show that there was a higher frequency of reactivity in the DF region in the sera from $N C$ patients $(p<0.05)$, while discrimination between active and inactive $N C$ was seen only in extracts from the $M G$ and $S P$ regions $(p<0.05)$. Using $R A P D$, the sample from the $D F$ region presented a greater increase compared to the other regions. A relationship between genetic polymorphisms among $\mathrm{T}$. solium metacestodes from different areas in Brazil and the differences in antibody detection in patients with NC were established.

Key words: cysticercosis - Taenia solium - RAPD - diagnosis - Brazil

Taenia solium is a parasite whose larvae (metacestodes) can be found in the central nervous system of humans, causing neurocysticercosis (NC). This parasitosis is a zoonotic disease that is endemic in the developing countries of Latin America, Asia and Africa (Sciutto et al. 2000, Pawlowski 2008, Raccurt et al. 2009, Flores Castro 2010, Praet et al. 2010, Ito et al. 2011). Cysticercosis has emerged as a cause of severe neurologic diseases in the United States that primarily affects immigrants from Latin America. Moreover, the relevance of cysticercosis as a public health problem is highlighted by local transmission (Sorvillo et al. 2011). Human cysticercosis is acquired accidentally by the ingestion of T. solium eggs and its transmission is related to a lack of sanitation, bad personal hygiene and the inadequate disposal of human faeces (Vianna et al. 1986, Huerta et al. 2008, Flisser \& Correa 2010).

$\mathrm{NC}$ is classified as active or inactive and inflammatory or non-inflammatory, according to the stage of metacestode development when viewed by neuroimaging tests associated with the presence or absence of a host immune response (Sotelo et al. 1985, Barcelos et al. 2007). The diagnosis of human NC is determined after the analysis of clinical, epidemiological, neuroimaging

Financial support: CNPq, CAPES, FAPEMIG

+ Corresponding author: costacruz@ufu.br

Received 5 April 2011

Accepted 23 August 2011 and immunological data (Del Brutto et al. 2001). The combination of enzyme linked immunosorbent assay (ELISA) and western blotting (WB) to detect specific antibodies against metacestodes extracts of T. solium in the serum samples or in the cerebrospinal fluid (CSF) of patients with $\mathrm{NC}$ represents a viable alternative for the diagnosis of the disease in developing countries (Shiguekawa et al. 2000, Barcelos et al. 2001, Sahu et al. 2009, Nunes et al. 2010).

Differences in the infectivity and the pathogenicity of $T$. solium metacestodes may be related to the genetic variability of the parasite (Campbell et al. 2006). Variance in T. solium metacestode DNA can generate antigenic variability according to clonal lineage behaviour (Maravilla et al. 2008).

The aim of the present study is to investigate the genetic polymorphisms in $T$. solium metacestodes from different Brazilian geographical areas and to relate them to each other using antibody recognition in the serum samples of NC patients.

\section{SUBJECTS, MATERIALS AND METHODS}

Parasites - T. solium metacestodes obtained from the skeletal muscles of naturally infected pigs were washed in saline solution $(0.15 \mathrm{M} \mathrm{NaCl})$ four times and were stored at $-70^{\circ} \mathrm{C}$ for subsequent analysis. The parasites were collected from one individual pig in each of the following Brazilian geographical areas: (i) Distrito Federal (DF), Central West Region, (ii) Bahia (BA), Northeast Region, (iii) Minas Gerais (MG) and (iv) São Paulo (SP), Southeast Region. The samples were collected when a pig with a massive infection was found in each area. 
Preparation of antigens - The saline extracts of T. solium metacestodes from different geographic areas were prepared as described by Costa et al. (1982) with some modifications. Briefly, 50 metacestodes from each area were disrupted in $5 \mathrm{~mL}$ distilled water in an ice bath for $5 \mathrm{~min}$, were homogenised for $4 \mathrm{~min}$ and were subsequently submitted to ultrasonic treatment (Thornton, Inpec Electronics, Brazil) at $40 \mathrm{kHz}$ for four periods of $30 \mathrm{~s}$ each in an ice bath. After adding $5 \mathrm{~mL}$ of $0.3 \mathrm{M}$ $\mathrm{NaCl}$, the ultrasonic treatment was repeated; the mixture was stirred at $4^{\circ} \mathrm{C}$ for $2 \mathrm{~h}$ and was centrifuged at $12,400 \mathrm{~g}$ at $4^{\circ} \mathrm{C}$ for $30 \mathrm{~min}$ (Du Pont SORVALL Products Newtown, Connecticut, USA). The supernatants were analysed for protein content using the Lowry method (Lowry et al. 1951) and were stored in aliquots at $-70^{\circ} \mathrm{C}$ until use in the ELISA and WB analyses.

Patients - With the exception of those individuals with Echinococcus granulosus, who came from Southern Brazil and the normal volunteers, who were recruited among students and their relatives, serum samples were collected from 157 individuals at the university hospital in Uberlândia. All individuals were from similar backgrounds and socio-economic conditions. Group 1 (G1) consisted of 49 patients (30 females and 19 males) with NC (19 active and 30 inactive) who were between 14-82 years of age (average age was 42 years) with a diagnosis based on clinical and epidemiological data, computerised tomography and/or magnetic resonance imaging and a positive immunological test (Del Brutto et al. 1996). Group 2 (G2) consisted of 68 individuals (40 females and 28 males) between two-71 years of age (average age was 36 years) who were monoinfected with the following helminths: Taenia sp. (20), Strongyloides stercoralis (20), Schistosoma mansoni (10), Hymenolepis nana (8) from the southeast area and E. granulosus (10) from the southern area. Group 3 (G3) (control) consisted of 40 volunteers (20 females and 20 males) between 21-80 years of age (average age was 32 years) who were apparently healthy based on clinical features. Although they came from an area with endemic cysticercosis (southeastern Brazil), none had household contact with $T$. solium infection or a previous history of taeniasis or cysticercosis. This group also underwent three faecal sample tests (Baermann 1917, Lutz 1919), which were negative.

ELISA - All reagents were tested previously and ELISA was carried out according to Shiguekawa et al. (2000). Polystyrene microplates (Corning, USA) were coated with the saline extracts at a concentration of $5 \mu \mathrm{g} /$ $\mathrm{mL}(50 \mu \mathrm{L} /$ well). Serum samples were diluted 1:200 and peroxidase-conjugated goat anti-human immunoglobulin $\mathrm{G}$ (IgG) (Fc chain specific) (Sigma, St. Louis, USA) was used at a titre of 3,000 for all antigens. The assay was developed by adding the enzyme substrate consisting of $0.03 \% \mathrm{H}_{2} \mathrm{O}_{2}$ (Merck, Germany) in $0.1 \mathrm{M}$ citrate- $\mathrm{Na}_{2} \mathrm{PO}_{4}$ buffer (pH 5.0) containing $0.4 \mathrm{mg} / \mathrm{mL}$ of o-phenylenediamine (Merck). After 15 min of incubation at room temperature (RT), the reaction was stopped by adding $2 \mathrm{~N}$ $\mathrm{H}_{2} \mathrm{SO}_{4}(25 \mathrm{~mL} /$ well $)$ and the absorbance was determined at $492 \mathrm{~nm}$ using a microplate reader (Titertek Multiskan, Flow Laboratories, USA). The cut-off was established using the mean of three non-reactive samples plus two standard deviations. The results were expressed as the reactivity index (RI), calculated by dividing the reading values of the test (absorbance $=$ optical density) by the cut-off (Pardini et al. 2002). All samples showing an RI $>1$ were considered positive.

$W B$ - The WB assay was performed according to Shiguekawa et al. (2000) with some modifications. All saline extracts were subjected to electrophoresis and were transferred to nitrocellulose membranes $(0.45 \mu \mathrm{m})$ (Sigma) as described by Towbin et al. (1979), using a semi-dry transfer apparatus (Multiphor II, PharmaciaLKB). Serum samples from 98 patients $(49,39$ and 10 individuals from $\mathrm{G} 1, \mathrm{G} 2$ and $\mathrm{G} 3$, respectively) were diluted 1:50 before analysis. Peroxidase-conjugated anti-human IgG (whole molecule) (Sigma) was used at a titre of 200. The results were considered positive when at least two or more immunodominant proteins $(18,24,28-32,39$ $42,47-52,64-68$ and $70 \mathrm{kDa}$ ) (Barcelos et al. 2007) were recognised by the serum samples.

Genomic DNA and random amplified polymorphic $D N A$ (RAPD) - Genomic DNA extraction was performed in metacestodes from each region using methods that were described by Casas et al. (1995) and modified by Gonzalez et al. (2002). The negative control consisted of DNA that was extracted from $10 \mathrm{mg}$ skeletal muscle derived from an uninfected pig. Briefly, the samples were homogenised in liquid nitrogen and were extracted in $50 \mu \mathrm{L}$ of lysis buffer (4 M guanidine isothiocyanate, $25 \mathrm{mM}$ sodium citrate, $\mathrm{pH} 7,0.5 \%$ sarcosyl and $1 \mathrm{mM}$ dithiothreitol) for $10 \mathrm{~min}$ at RT and were centrifuged at 4,000 $\mathrm{g}$. DNA was precipitated from the supernatant using one volume of isopropanol followed by another centrifugation at $11,750 \mathrm{~g}$ for $10 \mathrm{~min}$. DNA pellets were washed in $70 \%$ ethanol and were resuspended in water. The RAPD assay was carried out using $30 \mathrm{ng}$ of DNA template, $400 \mathrm{mM}$ of dNTPs (Amersham Biosciences, USA), $3 \mathrm{mM}$ of $\mathrm{MgCl}_{2}$ (Lab Trade, Brazil), 1.5 U of Taq DNA polymerase (Lab Trade, Brazil) and $1 \mathrm{nmol}$ of primers (35 decamer primers) (Gene Link, USA) (Table I). Sterile water was used as a non-DNA control for the reaction. Polymerase chain reaction amplification was performed using the following parameters: an initial denaturation of $5 \mathrm{~min}$ at $94^{\circ} \mathrm{C}, 35$ cycles of $94^{\circ} \mathrm{C}$ for $30 \mathrm{~s}, 36^{\circ} \mathrm{C}$ for $1 \mathrm{~min}$ and $72^{\circ} \mathrm{C}$ for $2 \mathrm{~min}$, and a final extension at $72^{\circ} \mathrm{C}$ for 10 min (Perkin Elmer, New Jersey, USA). Amplified products were analysed by electrophoresis in 2\% agarose gels (Acros Organics, Belgium) that were stained with ethidium bromide and visualised under ultraviolet light. RAPD band patterns were recorded and analysed giving each band a value of 1 (if present) or 0 (if absent). The bands were also compared against RAPD profiles of pork muscle as a control.

Statistical analysis - Analysis of the data was performed using the Statistics for Windows software (StatSoft, Inc 1993) and the Software Graph Pad Prism version 5.0 (Graph Pad Software, Inc 2007). To compare the frequency of antigenic markers recognised using WB and to determine the frequency of anti-T. solium metacestodes IgGs detected in serum samples using ELISA, the percentages of the revealed bands were tested by two proportions at a significance level of $5 \%(\mathrm{p}<0.05)$. 


\section{TABLE I}

Primers and polymorphic fragments by random amplified polymorphic DNA of Taenia solium metacestodes from different Brazilian geographical areas

\begin{tabular}{|c|c|c|}
\hline $\begin{array}{l}\text { Primer } \\
\text { sequence }\end{array}$ & $\begin{array}{c}\text { Brazilian } \\
\text { geographical } \\
\text { areas }\end{array}$ & $\begin{array}{l}\text { Size fragment } \\
\text { amplification } \\
\text { (pb) }\end{array}$ \\
\hline CAGGCCCTTC & - & - \\
\hline TGCCGAGCTG & - & - \\
\hline AGTCAGCCAC & $\begin{array}{l}\mathrm{DF} \\
\mathrm{BA}\end{array}$ & $\begin{array}{c}800,434 \\
103,244,326\end{array}$ \\
\hline AATCGGGCTG & - & - \\
\hline AGGGGTCTTG & - & - \\
\hline GGTCCCTGAC & - & - \\
\hline GAAACGGGTG & - & - \\
\hline GTGACGTAGG & - & - \\
\hline ACGGATCCTG & - & - \\
\hline GAGGATCCCT & - & - \\
\hline CCTGATCACC & - & - \\
\hline GGTGATCAGG & - & - \\
\hline CCGAATTCCC & - & - \\
\hline GGGAATTCGG & - & - \\
\hline CCGATATCCC & - & - \\
\hline GGGATATCGG & - & - \\
\hline GGATGAGACC & $\begin{array}{l}\mathrm{DF} \\
\mathrm{BA}\end{array}$ & $\begin{array}{l}1,000,244 \\
200,137\end{array}$ \\
\hline ACTGGGACTC & - & - \\
\hline AGCGTCCTCC & - & - \\
\hline ACGACCGACA & - & - \\
\hline GGCTCATGTG & - & - \\
\hline GGGCCACTCA & - & - \\
\hline GGAGAGACTC & - & - \\
\hline TCCACTCCTG & - & - \\
\hline CACAGAGGGA & - & - \\
\hline GGGTTTGGCA & $\begin{array}{l}\mathrm{MG} \\
\mathrm{SP}\end{array}$ & $\begin{array}{c}244,600,326 \\
326,244\end{array}$ \\
\hline CCCTAGACTG & - & - \\
\hline GGAGCCTCAG & - & - \\
\hline TCGCCAGCCA & $\begin{array}{l}\text { DF } \\
\text { BA } \\
\text { SP }\end{array}$ & $\begin{array}{c}1,000 \\
244,434 \\
500,800,1,191\end{array}$ \\
\hline ACGGGAGCAA & - & - \\
\hline AGCAGCGCAC & - & - \\
\hline CAAACGTGGG & - & - \\
\hline AGACGATGGG & $\begin{array}{l}\mathrm{DF} \\
\mathrm{BA}\end{array}$ & $\begin{array}{c}800,600,400,326 \\
400,326\end{array}$ \\
\hline AAGCCTGCGA & - & - \\
\hline GGGTCTCGGT & $\begin{array}{l}\text { DF } \\
\text { BA }\end{array}$ & $\begin{array}{c}1,434 \\
800\end{array}$ \\
\hline
\end{tabular}

BA: Bahia; DF: Distrito Federal; MG: Minas Gerais; SP: São Paulo; -: non amplification.
The genetic distances among the samples of $T$. solium metacestodes were analysed using STAT 4.5 software using percentage of disagreement and unweighted pairgroup method using arithmetic average.

Ethics - This study received approval from the Research Ethics Committee of the Federal University of Uberlândia, MG, Brazil.

\section{RESULTS}

All serum samples were analysed using ELISA and the saline extracts of $T$. solium metacestodes that were collected from different geographic areas (Fig. 1). The data shows that the RI was significantly higher in the $\mathrm{NC}$ patient sera $(\mathrm{G} 1)(\mathrm{p}<0.05)$ when compared with the control group (G3) or the other helminths group (G2) with the exception of patients with an E. granulosus infection.

Table II shows the reactivity frequency that was obtained using ELISA and WB assays with regard to the four antigenic extracts in the serum samples of G1, G2 and G3. ELISA showed reactivity differences between the patients with active and inactive $\mathrm{NC}$ (G1) only in those antigenic extracts from the MG and SP geographic areas $(\mathrm{p}<0.05)$. In $\mathrm{G} 2$, there was higher frequency $(90 \%$ in the extracts from the DF region and $70 \%$ in the other antigens) of reactivity in the ELISA assays for samples from E. granulosus patients $(\mathrm{p}<0.05)$. The active NC serum samples reacted in the range of $84.2-94.7 \%$ in the WB assays when the different antigens were used. In contrast, all serum samples from individuals with inactive $\mathrm{NC}$, other parasitosis and the apparently healthy volunteers had no reaction with any of the antigens that were analysed (Table II).

The frequency of the different antigens that were recognised by the IgG antibodies in WB from patients with active NC is shown in Fig. 2. In patients with active NC, there was a variation of reactivity among the different antigens (DF, BA, MG and SP). The $24 \mathrm{kDa}$ peptide was recognised with the DF, BA and MG antigens; peptides from the 28-32 kDa range were recognised with the $\mathrm{DF}, \mathrm{MG}$ and SP antigens, whereas peptides from the 39-42 kDa range were recognised with the $\mathrm{MG}$ and $\mathrm{SP}$ antigens. The peptides from the $47-52 \mathrm{kDa}$ and $64-68 \mathrm{kDa}$ range were recognised with all of the antigens that were analysed.

The analysis of RAPD profiles indicated the existence of a genetic polymorphism between different Brazilian geographical areas. In the banding patterns generated by RAPD, only amplicons 103, 137, 200, 244, 326, 400, 434, $500,600,800,1,000,1,191$ and 1,434 were polymorphic and as seen in Table I, only cysticerci from DF generated bands of 800 and $434 \mathrm{bp}$, whereas cysticerci from BA produced amplicons of 103, 244 and 326 bp and those from MG and SP did not generate these amplicons. The reproducibility of the RAPD analysis was confirmed. Genetic relationships among metacestodes that were collected from different Brazilian geographical areas using the 13 RAPD markers are shown in a dendrogram (Fig. 3). The sample from the DF region exhibits a greater difference in relation to the other samples and is followed by the sample from the BA region, whereas the samples from the SP and $\mathrm{MG}$ regions exhibit a smaller difference. 
A

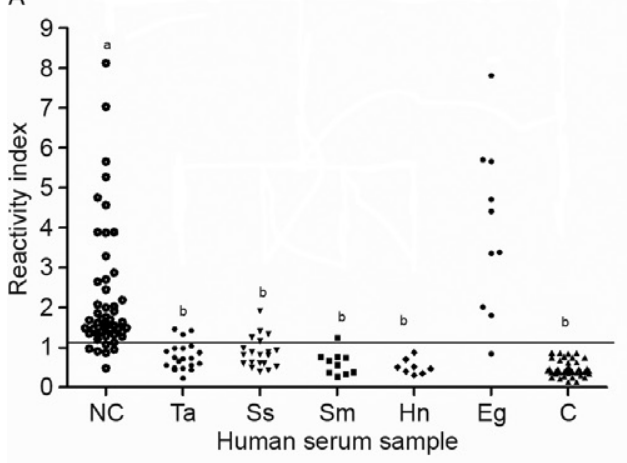

B

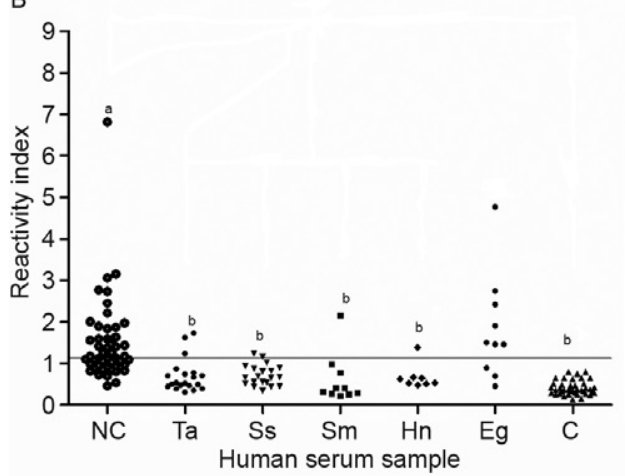

C

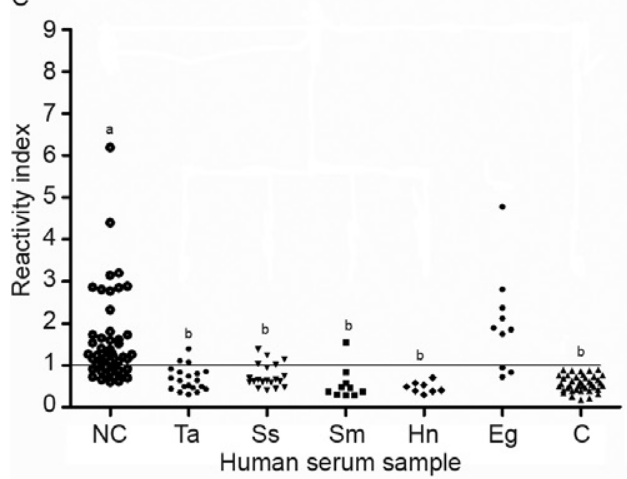

$\mathrm{D}$

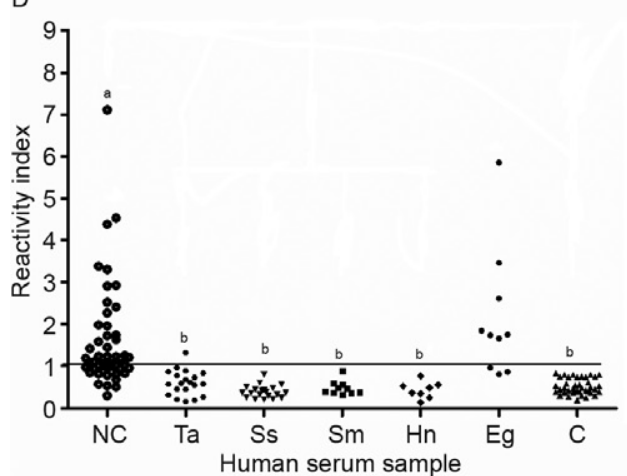

Fig. 1: levels of specific immunoglobulin G by enzyme linked immunosorbent assay using saline extracts of Taenia solium metacestodes from (A) Distrito Federal, (B) Bahia, (C) Minas Gerais, (D) São Paulo, different Brazilian geographical areas, in human serum samples. C: control-apparently healthy volunteers-Group 3; Eg: Echinococcus granulosus-Group 2; Hn: Hymenolepis nana; NC: neurocysticercosis-Group 1; Sm: Schistosoma mansoni; Ss: Strongyloides stercoralis; Ta: Taenia sp. Different letters "a" and "b" indicates the significant statistical differences $(\mathrm{p}<0.05)$.

\section{DISCUSSION}

Differences in the reactivity of IgG antibodies in serum samples from patients with $\mathrm{NC}$ were demonstrated using ELISA and WB for antigenic extracts from the four populations of $T$. solium metacestodes that were collected from different geographical areas of Brazil. A higher frequency of positive samples from patients with $\mathrm{NC}$ was observed in the antigen extracts from the DF region in the ELISA assay. Subsequently, discrimination between serum samples of patients with active and inactive forms of $\mathrm{NC}$ was possible in extracts from $\mathrm{MG}$ and $\mathrm{SP}$ regions and there was a low reactivity of samples from patients with inactive NC. Espinoza et al. (1986) and Barcelos et al. (2005) have shown that in paired samples of CSF and in serum from patients with active and inactive $\mathrm{NC}$, analysed by ELISA, there are higher IgG antibody levels in samples from the patients with active NC.

The results of serologic tests for the diagnosis of $\mathrm{NC}$ are directly influenced by differences in biological samples, if total or purified antigenic extracts are used, the patient's origin and the clinical phases of NC. This could explain why the efficiency of these tests varies according to the published reports (Del Brutto et al. 1996, Schantz 2006). In this study, ELISA and WB assays using the saline extract of T. solium metacestodes showed a high sensitivity. ELISA had a low specificity and WB demonstrated specificity for the detection of specific bands $(\leq 70 \mathrm{kDa})$ in the serum samples from patients with active NC. Using the saline extract of $T$. solium metacestodes in our study, WB identified four of the seven antigenic markers $(18,24,39-42$ and $50 \mathrm{kDa}$ ) that are similar to the glycoproteins, described by Tsang et al. (1989), for the diagnosis of NC. In this study, the highest reactivity was found with $64-68 \mathrm{kDa}$ antigens. Shiguekawa et al. (2000) and Barcelos et al. (2007) showed that the 64-68 kDa antigens were immunodominant in serum samples. Analysing paired CSF and serum samples from NC patients, Simac et al. (1995) showed an additional 60-75 $\mathrm{kDa}$ band in CSF samples and explained this finding by referring to a Miller et al. (1985) publication, which proposed that the intrathecal secretion of specific antibodies was responsible for results such as these. The low sensitivity of the WB assay of serum samples from patients with inactive $\mathrm{NC}$ that was observed in this study was previously reported by our group (Barcelos et al. 2007).

The cross-reactivity observed in serum samples from patients infected by other helminth species using ELISA varied according to the four T. solium metacestodes antigens used. The group diagnosed with other parasitosis is representative of the general population, particularly in Brazil, where parasitic diseases are highly prevalent. Therefore, cross-reactions may occur when screening for active NC using tests, such as ELISA and/or WB, which require further confirmation using antigens with more specificity, e.g., purified antigens (Machado et al. 2007). The presence of common antigenic epitopes in different species of parasites has been described (Shiguekawa et al. 2000, Ishida et al. 2003). The higher cross-reactivity with E. granulosus can be explained by its phylogenetic closeness with Taenia parasites (Hoberg 2006). 
TABLE II

Reactivity frequency by enzyme linked immunosorbent assay (ELISA) and Western Blotting (WB)

\begin{tabular}{|c|c|c|c|c|c|c|c|c|}
\hline \multirow[b]{3}{*}{ Patient groups } & \multicolumn{8}{|c|}{ Saline antigenic extracts of Taenia solium metacestodes } \\
\hline & \multicolumn{2}{|c|}{ Distrito Federal } & \multicolumn{2}{|c|}{ Bahia } & \multicolumn{2}{|c|}{ Minas Gerais } & \multicolumn{2}{|c|}{ São Paulo } \\
\hline & $\begin{array}{c}\text { ELISA } \\
\text { n/N (\%) }\end{array}$ & $\begin{array}{c}\text { WB } \\
\text { n/N (\%) }\end{array}$ & $\begin{array}{l}\text { ELISA } \\
\text { n/N }(\%)\end{array}$ & $\begin{array}{c}\text { WB } \\
\mathrm{n} / \mathrm{N}(\%)\end{array}$ & $\begin{array}{c}\text { ELISA } \\
\text { n/N }(\%)\end{array}$ & $\begin{array}{c}\text { WB } \\
\mathrm{n} / \mathrm{N}(\%)\end{array}$ & $\begin{array}{c}\text { ELISA } \\
\text { n/N }(\%)\end{array}$ & $\begin{array}{c}\text { WB } \\
\mathrm{n} / \mathrm{N}(\%)\end{array}$ \\
\hline \multicolumn{9}{|l|}{$\mathrm{NC}$} \\
\hline Active & $18 / 19(94.7)$ & $17 / 19(89.5)$ & $12 / 19(63.2)$ & $16 / 19(84.2)$ & $17 / 19(89.5)^{a}$ & $17 / 19(89.5)$ & $15 / 19(78.9)^{b}$ & $18 / 19(94.7)$ \\
\hline Inactive & $26 / 30(86.7)$ & $0 / 30(0)$ & $22 / 30(73.3)$ & $0 / 30(0)$ & $18 / 30(60)^{a}$ & $0 / 30(0)$ & $18 / 30(60)^{b}$ & $0 / 30(0)$ \\
\hline \multicolumn{9}{|l|}{ Other parasitosis } \\
\hline Taeniasis & $4 / 20(20)$ & $0 / 7(0)$ & $3 / 20(15)$ & $0 / 10(0)$ & $3 / 20(15)$ & $0 / 10(0)$ & $1 / 20(5)$ & $0 / 10(0)$ \\
\hline Strongyloidiasis & $5 / 20(25)$ & $0 / 10(0)$ & $3 / 20(15)$ & $0 / 10(0)$ & $5 / 20(25)$ & $0 / 10(0)$ & $0 / 20(0)$ & $0 / 10(0)$ \\
\hline Schistosomiasis & $1 / 10(10)$ & $0 / 8(0)$ & 1/10 (10) & $0 / 8(0)$ & 1/10 (10) & $0 / 8(0)$ & $0 / 10(0)$ & $0 / 8(0)$ \\
\hline Hymenolepiasis & 0/8 (0) & $0 / 4(0)$ & $1 / 8(12.5)$ & $0 / 4(0)$ & 0/8 (0) & $0 / 4(0)$ & $0 / 8(0)$ & $0 / 4(0)$ \\
\hline Hydatidosis & $9 / 10(90)^{c}$ & $0 / 10(0)$ & $7 / 10(70)^{c}$ & $0 / 10(0)$ & $7 / 10(70)^{c}$ & $0 / 10(0)$ & $7 / 10(70)^{c}$ & $0 / 10(0)$ \\
\hline Controls & $0 / 40(0)$ & $0 / 10(0)$ & $0 / 40(0)$ & $0 / 10(0)$ & $0 / 40(0)$ & $0 / 10(0)$ & $0 / 40(0)$ & 0/10 (0) \\
\hline
\end{tabular}

$a, b$ : difference by two proportions $(\mathrm{p}<0.05)$ between active neurocysticercosis $(\mathrm{NC})$ and inactive NC with Minas Gerais and São Paulo extracts of T. solium metacestodes, respectively; $c$ : difference by two proportions $(\mathrm{p}<0.05)$ between Distrito Federal extracts of T. solium metacestodes and others extracts; $\mathrm{n} / \mathrm{N}$ : serum sample reagents/total serum sample analyzed.

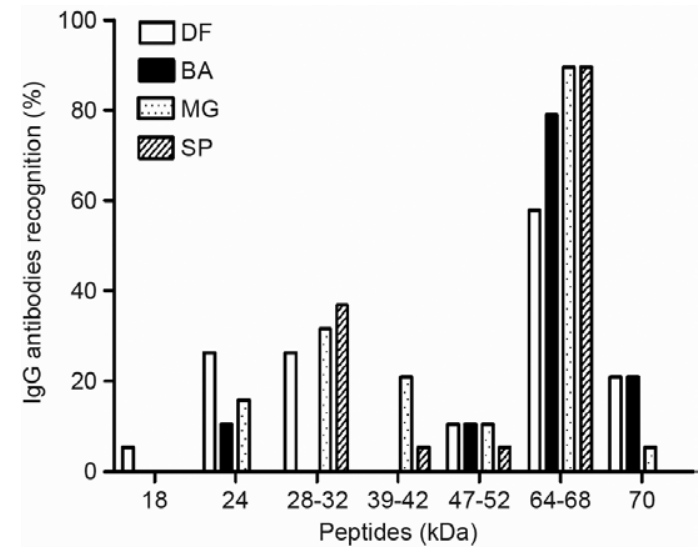

Fig. 2: percentage of reactivity frequency of serum samples from patients with active neurocysticercosis by western blotting among different antigens. BA: Bahia; DF: Distrito Federal; IgG: immunoglobulin G; MG: Minas Gerais; SP: São Paulo.

The present study demonstrates DNA polymorphism in T. solium metacestode samples from different geographical regions in Brazil. Martinez-Hernandez et al. (2009) analysed the genetic structure of the T. solium population based on previously published molecular data of mitochondrial and nuclear ribosomal DNA sequences that were deposited in the GenBank from Africa, Asia, Latin America and Oceania and the report demonstrated polymorphisms in cysticerci sequences from Brazil and other countries and provided gene flow values between them. RAPD employing T. solium cysticerci that was recovered from naturally infected

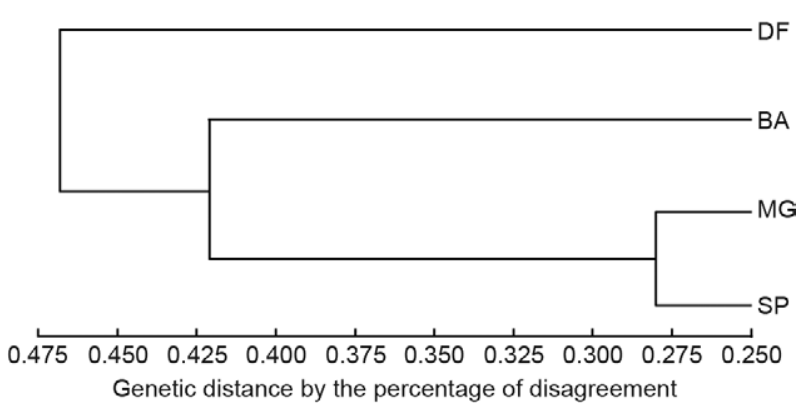

Fig. 3: genetic relation among metacestodes from different Brazilian geographical areas. Distances based in the percentage of disagreement of 13 random amplified polymorphic DNA markers grouped randomly by unweighted pair group method with averages for the four genotypes of Taenia solium metacestodes from different geographic locations in Brazil. BA: Bahia; DF: Distrito Federal; MG: Minas Gerais; SP: São Paulo.

pigs from Mexico, Honduras, Madagascar and Tanzania showed several fixed alleles with linkage disequilibrium in some parasites, suggesting the existence of local lineages (Maravilla et al. 2003, Vega et al. 2003). Genetic variability of the $45 \mathrm{~W}$ gene family has been demonstrated between Chinese and Mexican T. solium (Zheng et al. 2008). In the present study, the parasite material originated from only one pig and it is possible that antigenic variation exists within the parasites of one state. Moreover, even though the same protocol has been used for collecting and isolating the antigens, differences in antigenic properties can also be due to other factors, such as the age of the cysts and viability. 
Because a large number of potential nuclear and mitochondrial markers can be generated by RAPD using readily available primers (Williams et al. 1990), it is possible that some polymorphic loci found using this technique are translated to a certain phenotypic variability (i.e., some antigenic variants). Therefore, in the present study, although genetically divergent from other populations that were analysed, cysticerci from the DF region were strongly recognised by patients with NC. Furthermore, knowledge of the genetic structure of $T$. solium may be applied to understanding its epidemiology and transmission because differences in the infectivity and pathogenicity of $T$. solium metacestodes, which are manifested by different antigen recognition by host antibodies, may imply genetic variability of the parasite (Campbell et al. 2006, Hinojosa-Juarez et al. 2008) and a more complex disease presentation in areas where $\mathrm{NC}$ predominates and in regions where there is a similar prevalence of both clinical forms (Ito et al. 2003). Because of its genetic variability, $T$. solium could be a significant source of the clinical heterogeneity observed in this disease and could contribute to the difficulties encountered in the design of reliable immunodiagnostic tools and vaccines (Vega et al. 2003, Sciutto et al. 2008). RAPD technology has been an effective tool for the study of intra-species genetic variability. Interestingly, cysticerci from the DF region, which presented more variability, as shown in the dendrogram (Fig. 3), exhibited more reactivity with serum samples from patients with active and inactive NC.

\section{REFERENCES}

Baermann G 1917. Eine einfache methods zur Auffindung von Ankylostomum (Nematoden) larven in endproben, Mededeel mit. $h$. Geneesk, Lab Weltevreden Feestbundel, Batavia, p. 41-47.

Barcelos ISC, Mineo JR, de Oliveira Silva DA, Ferreira MS, de Moura LP, Biondi GF, Costa-Cruz JM 2001. Detection of IgG in cerebrospinal fluid for diagnosis of neurocysticercosis: evaluation of saline and SDS extracts from Taenia solium and Taenia crassiceps metacestodes by ELISA and immunoblot assay. Trop Med Int Health 6: 219-226.

Barcelos ISC, Ferreira MS, Moura LP, Biondi GF, Costa-Cruz JM 2005. Use of the paired samples (cerebrospinal fluid and serum) in immunodiagnostic of active and inactive human neurocysticercosis. Mem Inst Oswaldo Cruz 100: 427-429.

Barcelos ISC, Moura LP, Costa VP, Ferreira MS, Costa-Cruz JM 2007. Taenia solium metacestode immunodominant peptides recognized by $\mathrm{IgG}$ antibodies in cerebrospinal fluid and serum paired samples from patients with active and inactive neurocysticercosis. Mem Inst Oswaldo Cruz 102: 713-717.

Campbell G, Garcia HH, Nakao M, Ito A, Craig PS 2006. Genetic variation in Taenia solium. Parasitol Int 55 (Suppl.): S121-S126.

Casas I, Powell L, Klapper PE, Cleator GM 1995. New method for the extraction of viral RNA and DNA from cerebrospinal fluid for use in the polymerase chain reaction assay. J Virol Methods 53: 25-36.

Costa JM, Ferreira AW, Makino MM, Camargo ME 1982. Spinal fluid immunoenzymatic assay (ELISA) for neurocysticercosis. Rev Inst Med Trop Sao Paulo 24: 337-341.

Del Brutto OH, Wadia NH, Dumas M, Cruz M, Tsang VCW, Schantz PM 1996. Proposal of diagnostic criteria for human cysticercosis and neurocysticercosis. J Neurol Sci 142: 1-6.

Del Brutto OH, Rajshekhar V, White AC Jr, Tsang VC, Nash TE, Takayanagui OM, Schantz PM, Evans CA, Flisser A, Correa D,
Botero D, Allan JC, Sarti E, Gonzalez AE, Gilman RH, Garcia HH 2001. Proposed diagnostic criteria for neurocysticercosis. Neurology 57: 177-183.

Espinoza B, Ruiz-Palacios G, Tovar A, Sandoval MA, Plancarte A, Flisser A 1986. Characterization by enzyme-linked immunosorbent assay of the humoral immune response in patients with neurocysticercosis and its application in immunodiagnosis. J Clin Microbiol 24: 536-541.

Flisser A, Correa D 2010. Neurocysticercosis may no longer be a public health problem in Mexico. PLoS Negl Trop Dis 4: e831.

Flores Castro R 2010. Current situation of the most frequent zoonosis in the world. Gac Med Mex 146: 423-429.

Gonzalez LM, Montero E, Puente S, López-Velez R, Hernández M, Sciutto E, Harrison LJS, Parkhouse RME, Gárate T 2002. PCR tools for the differential diagnosis of Taenia saginata and Taenia solium taeniasis/cysticercosis from different geographical locations. Diagn Microbiol Infect Dis 42: 243-249.

Hinojosa-Juarez AC, Sandoval-Balanzario M, McManus DP, Monroy-Ostria A 2008. Genetic similarity between cysticerci of Taenia solium isolated from human brain and from pigs. Infect Genet Evol 8: 653-656.

Hoberg EP 2006. Phylogeny of Taenia: species definitions and origins of human parasites. Parasitol Int 55 (Suppl): S23-S30.

Huerta M, Avila R, Jiménez HI, Díaz R, Díaz J, Díaz Huerta ME, Hernández M, Martinez JJ, Garate T, Gómez E, Abad T, Fragoso G, Fleury A, Sciutto E 2008. Parasite contamination of soil in households of a Mexican rural community endemic for neurocysticercosis. Trans R Soc Trop Med Hyg 102: 374-379.

Ishida MMI, Rubinsky-Elefant G, Ferreira AW, Hoshino-Shimizu S, Vaz AJ 2003. Helminth antigens (Taenia solium, Taenia crassiceps, Toxocara canis, Schistosoma mansoni and Echinococcus granulosus) and cross-reactivities in human infections and immunized animals. Acta Trop 89: 73-84.

Ito A, Yamasaki H, Nakao M, Sako Y, Okamoto M, Sato MO, Nakaya K, Margono SS, Ikejima T, Kassuku AA, Afonso SM, Ortiz WB, Plancarte A, Zoli A, Geerts S, Craig PS 2003. Multiple genotypes of Taenia solium ramifications for diagnosis, treatment and control. Acta Trop 87: 95-101.

Ito A, Okamoto M, Li T, Wandra T, Dharmawan NS, Swastika KI, Dekumyoy P, Kusolsuk T, Davvajav A, Davaasuren A, Dorjsuren T, Mekonnen SM, Negasi ZH, Yanagida T, Sako Y, Nakao M, Nakaya K, Lavikainen AJ, Nkouawa A, Mohammadzadeh T 2011. The first workshop towards the control of cestode zoonoses in Asia and Africa. Parasit Vectors 4: 114.

Lowry VH, Rosebrouch NJ, Farr AL, Randal RJ 1951. Protein measurement with the Folin phenol reagent. J Biol Chem 193: 265-275.

Lutz AV 1919. O Schistosomum mansoni e a schistosomose segundo observações feitas no Brasil pelo Dr. Adolpho Lutz. Mem Inst Oswaldo Cruz 11: 121-155.

Machado GA, Santiago FM, Mineo JR, Costa-Cruz JM 2007. Assessment of antigenic fractions of varying hydrophobicity from Taenia solium metacestodes for the diagnosis of human neurocysticercosis. Trop Med Int Health 12: 1369-1376.

Maravilla P, Souza V, Valera A, Romero-Valdonivos M, Lopez-Vidal Y, Dominguez-Alpizar JL, Ambrosio J, Kawa S, Flisser A 2003. Detection of genetic variation in Taenia solium. J Parasitol 89: 1250-1254.

Maravilla P, Gonzalez-Guzman R, Zuñiga G, Peniche A, DominguezAlpizar JL, Reyes-Montes R, Flisser A 2008. Genetic polymorphism in Taenia solium cysticerci recovered from experimental infections in pigs. Infect Genet Evol 8: 213-216. 
Martinez-Hernandez F, Jimenez-Gonzalez DE, Chenillo P, AlonsoFernandez C, Maravilla P, Flisser A 2009. Geographical widespread of two lineages of Taenia solium due to human migrations: can population genetic analysis strengthen this hypothesis? Infect Genet Evol 9: 1108-1114.

Miller BL, Staugaitis SM, Tourtellotte WW, Shapshak P, Goldberg M, Heiner D, Weil M 1985. Intra-blood-brain barrier IgG synthesis in cerebral cysticercosis. Arch Neurol 42: 782-784.

Nunes DS, da Silva Ribeiro V, Manhani MN, Costa-Cruz JM 2010. Jacalin-unbound fraction of Taenia saginata in immunodiagnosis of neurocysticercosis in human cerebrospinal fluid. Diagn Microbiol Infect Dis 68: 259-264.

Pardini AX, Peralta RH, Vaz AJ, Machado LD, Peralta JM 2002. Use of Taenia crassiceps cysticercus antigen preparations for detection of antibodies in cerebrospinal fluid samples from patients with neurocysticercosis (Taenia solium). Clin Diag Lab Immunol 9: 190-193.

Pawlowski ZS 2008. Control of neurocysticercosis by routine medical and veterinary services. Trans R Soc Trop Med Hyg 102: 228-232.

Praet N, Kanobana K, Kabwe C, Maketa V, Lukanu P, Lutumba P, Polman K, Matondo P, Speybroeck N, Dorny P, Sumbu J 2010. Taenia solium cysticercosis in the Democratic Republic of Congo: how does pork trade affect the transmission of the parasite? PLoS Negl Trop Dis 4: e817.

Raccurt CP, Agnamey P, Boncy J, Henrys JH, Totet A 2009. Seroprevalence of human Taenia solium cysticercosis in Haiti. J Helminthol 83: 113-116.

Sahu PS, Parija SC, Narayan SK, Kumar D 2009. Evaluation of an IgG-ELISA strategy using Taenia solium metacestode somatic and excretory-secretory antigens for diagnosis of neurocysticercosis revealing biological stage of the larvae. Acta Trop 110: 38-45.

Schantz PM 2006. Progress in diagnosis, treatment and elimination of echinococcosis and cysticercosis. Parasitol Int (Suppl.) 55: S7-S13.

Sciutto E, Fragoso G, Fleury A, Laclette JP, Sotelo J, Aluja A, Vargas L, Larralde C 2000. Taenia solium disease in humans and pigs: an ancient parasitosis disease rooted in developing countries and emerging as a major health problem of global dimensions. Microbes Infect 2: 1875-1890.
Sciutto E, Fragoso G, de Aluja AS, Hernández M, Rosas G, Larralde C 2008. Vaccines against cysticercosis. Curr Top Med Chem 8: 415-423.

Shiguekawa KYM, Mineo JR, Moura LP, Costa-Cruz JM 2000. ELISA and western blotting tests in the detection of $\mathrm{IgG}$ antibodies to Taenia solium metacestodes in serum samples in human neurocysticercosis. Trop Med Int Health 5: 443-449.

Simac C, Michel P, Andriantsimahavandy A, Esterre P, Michault A 1995. Use of enzyme-linked immunosorbent assay and enzymelinked immunoelectrotransfer blot for the diagnosis and monitoring of neurocysticercosis. Parasitol Res 81: 132-136.

Sorvillo F, Wilkins P, Shafir S, Eberhard M 2011. Public health implications of cysticercosis acquired in the United States. Emerg Infect Dis 17: 1-6.

Sotelo J, Guerrero V, Rubio F 1985. Neurocysticercosis: a new classification based on active and inactive forms. A study of 753 cases. Arch Intern Med 145: 442-445.

Towbin H, Staehelin T, Gordon J 1979. Electrophoretic transfer of proteins from polyacrylamide gels to nitrocellulose sheets: procedure and some applications. Proc Natl Acad Sci USA 76: 4350-4354.

Tsang VC, Brand JA, Boyer AE 1989. An enzyme-linked immunoelectrotransfer blot assay and glycoprotein antigens for diagnosing human cysticercosis (Taenia solium). J Infect Dis 159: 50-59.

Vega R, Piñero D, Ramanankandrasana B, Dumas M, Bouteille B, Fleury A, Sciutto E, Larralde C, Fragoso G 2003. Population genetic structure of Taenia solium from Madagascar and Mexico: implications for clinical profile diversity and immunological technology. Int J Parasitol 33: 1479-1485.

Vianna LG, Macêdo V, Costa JM, Mello P, Souza D 1986. Estudo soroepidemiológico da cisticercose humana em Brasília, Distrito Federal. Rev Soc Bras Med Trop 19: 149-156.

Williams JGK, Kubelik AR, Livak KJ, Rafalski JA, Tingey SV 1990. DNA polymorphisms amplified by arbitrary primers are useful as genetic markers. Nucleic Acids Res 18: 6531-6535.

Zheng Y, Cai X, Luo X, Zhang D, Jing Z 2008. Genetic variability of the $45 \mathrm{~W}$ gene family between Chinese and Mexican Taenia solium. Am J Trop Med Hyg 78: 946-948. 